\title{
Recent Advances in the Synthesis of 2-Substituted Oxetanes
}

\author{
Owen A. Davis, James A. Bull* \\ Department of Chemistry, Imperial College London, South Kensington, London SW7 2AZ, UK. \\ E-mail: j.bull@imperial.ac.uk.
}

Received: The date will be inserted once the manuscript is accepted.

\begin{abstract}
Recent interest in oxetanes in medicinal chemistry and as synthetic intermediates has led to the development of a number of methods for the synthesis of more functionalized and highly substituted oxetane derivatives. Here we review cyclization approaches for the preparation of 2-substituted oxetanes. Methods involving $\mathrm{C}-\mathrm{O}$ bond formation, as well as recently developed $\mathrm{C}-\mathrm{C}$ bond forming cyclization strategies are highlighted.
\end{abstract}

Key words: oxetanes, heterocycles, cyclization, ethers, insertion

The synthesis of oxetanes, 4-membered cyclic ethers, poses a challenge due to the combination of inherent ring strain and poor kinetics of cyclization. Recent interest in the properties of these small rings has prompted the development of a variety of new methods for their synthesis. Oxetanes find extensive use in polymer chemistry, ${ }^{1}$ and are increasingly used as synthetic intermediates in ring opening or rearrangement reactions. ${ }^{2,3}$ Moreover, the incorporation of oxetanes has been shown to improve physicochemical properties of drug-like molecules. ${ }^{4}$ Carreira has extensively investigated 3,3-disubstituted oxetanes as polar replacements for carbonyl and gemdimethyl groups. ${ }^{5}$ Synthetic and stability studies of these substrates prompted a dramatic increase in the use of 3- and 3,3-disubstituted oxetanes in medicinal chemistry programs. Although the oxetane motif is embedded in a number of biologically important natural products, ${ }^{6}$ previous studies on oxetane derivatives in drug discovery have been limited. ${ }^{7}$ Oxetanes still continue to provide unexplored chemical space to be investigated in this context.

While achiral 3-substituted oxetanes have become more accessible, ${ }^{4,5,8}$ synthetic limitations remain for 2substituted derivatives, which introduce a chiral center, and more highly substituted examples. These more complex structures offer additional vectors to be exploited in medicinal chemistry, and more varied substitution for use as synthetic intermediates. This article will summarise some recent synthetic advances towards the formation of 2-substituted oxetanes, and highlight our recent contributions. Selected recent examples of the following reaction classes are presented (Scheme 1):
a) $\mathrm{C}-\mathrm{O}$ bond forming cyclization
b) ring expansion of epoxides
c) Paternò-Büchi reaction: [2+2] photochemical cycloaddition
d) $\mathrm{C}-\mathrm{C}$ bond forming cyclization, highlighting recent work from our group.

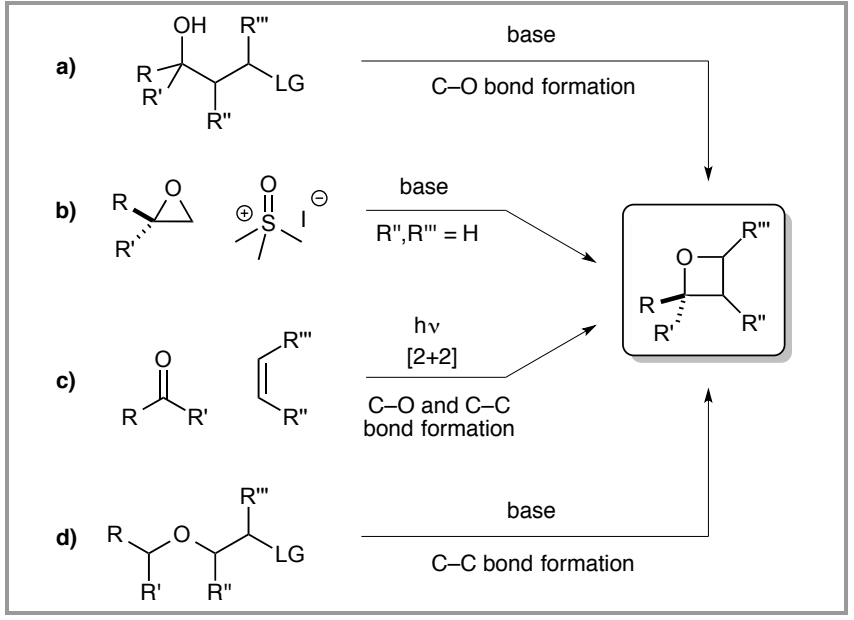

Scheme 1 Synthetic approaches to 2-substituted oxetanes.

The most recent applications of intramolecular Williamson etherification have occurred in the synthesis of spirocyclic oxetanes. ${ }^{9}$ For example, 2'-spirooxetane ribonucleoside derivatives have been developed to target the hepatitis $\mathrm{C}$ virus. ${ }^{10}$ In addition, Carreira has developed syntheses of various spirocyclic oxetanes as novel chemical modules. ${ }^{11} \mathrm{~A}$ recent example was the preparation of an interesting oxetane 2-carboxylate that was spiro-linked with an azetidine (Scheme 2a). ${ }^{12}$ Addition of furyllithium to an azetidine aldehyde afforded the cyclization precursor. Cyclization to the spiro-oxetane occurred successfully under mild basic conditions $\left(\mathrm{K}_{2} \mathrm{CO}_{3}\right.$, $\mathrm{MeOH})$. This choice of conditions for cyclization was crucial for this substrate as the use of $\mathrm{KO} t \mathrm{Bu}$ promoted a Grob fragmentation to give a 3-exomethylene azetidine. The furan substituent was then oxidized to afford the desired carboxylic acid.

An attractive route to suitable precursors for cyclization to oxetanes is the opening of epoxides with an ylide, which is followed directly by ring closure. $^{13}$ In 2009 Shibasaki reported a catalytic enantioselective one-pot synthesis of oxetanes from prochiral ketones via the epoxide (Scheme 2b). ${ }^{14}$ This involved the formation of the chiral epoxide in excellent ee using a chiral heterobimetallic complex and one equivalent of the Corey-Chaykovsky reagent. A second equivalent of the sulfoxonium ylide effected the ring expansion to the oxetane. The enantiopurity was further amplified in the second step due to a partial kinetic resolution of the intermediates. 2,2Disubstituted oxetanes were obtained from methyl ketones with $99 \%$ ee and in excellent yield. 


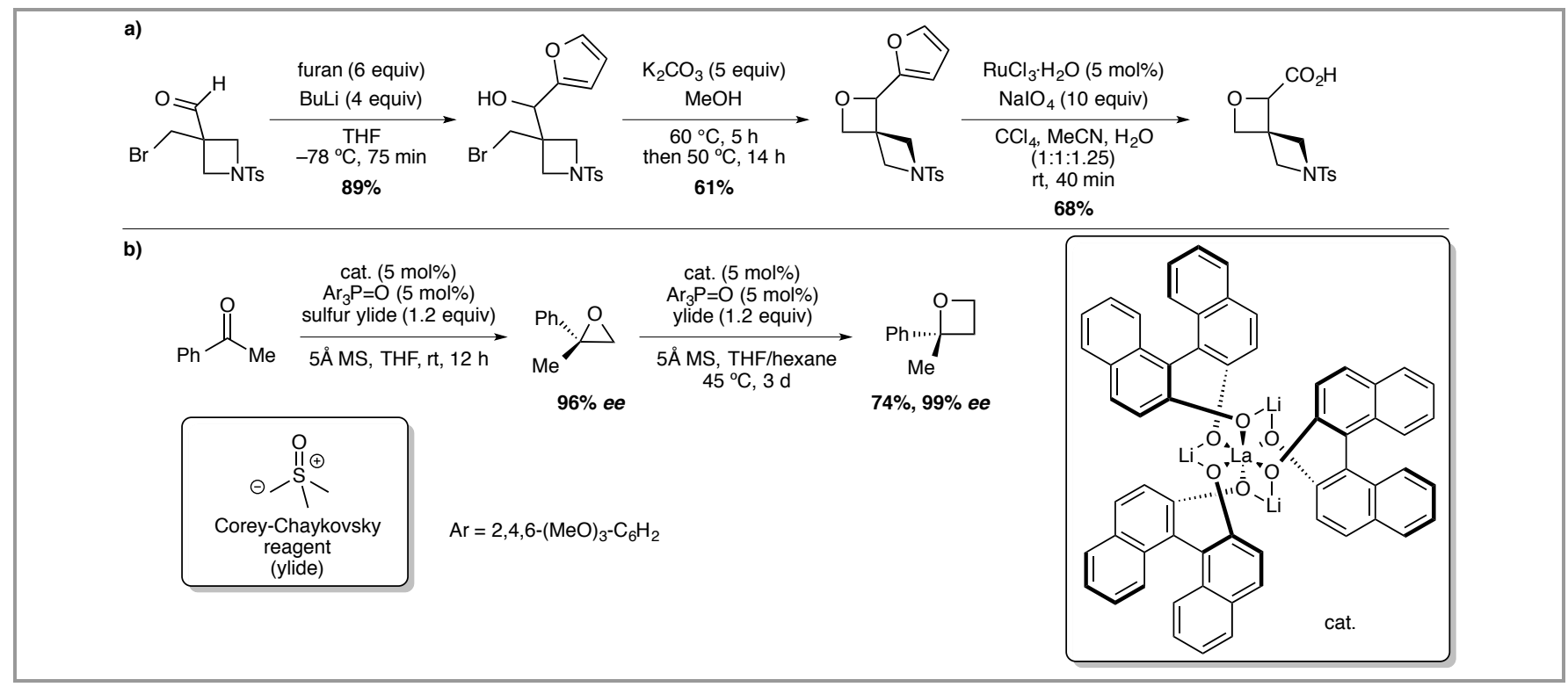

Scheme 2 a) Carreira's synthesis of spiro-linked oxetane-azetidine by Williamson etherification. b) Shibasaki's enantioselective synthesis of oxetanes from ketones.

Another classical approach to oxetane synthesis is the Paternò-Büchi photochemical [2+2] cycloaddition, ${ }^{15}$ which forms both $\mathrm{C}-\mathrm{O}$ and $\mathrm{C}-\mathrm{C}$ bonds via diradical species. In 2009, based on extensive previous work, Bach reported a general procedure for the synthesis of 3-(silyloxy)oxetanes and protected 3-aminooxetanes. This was achieved by irradiating aromatic aldehydes and silyl enols or $N$-acyl enamines, respectively, with ultraviolet light (Scheme 3a). ${ }^{16}$ Good yields were obtained and reactions occurred with high diastereoselectivity, with a cis-configuration between the aromatic and silyl ether/amine being favoured.

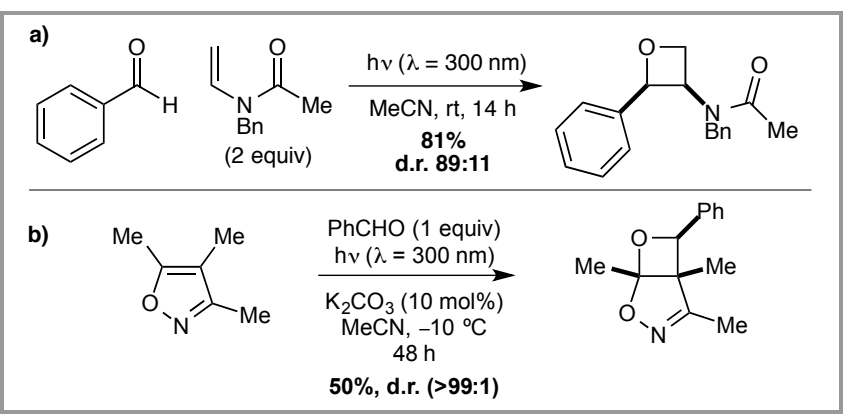

Scheme 3 Paternò-Büchi photochemical [2+2] cycloadditions.

In 2011, Griesbeck reported that certain methylsubstituted isoxazoles were capable of undergoing the Paternò-Büchi reaction with a variety of aromatic aldehydes (Scheme 3b). ${ }^{17}$ Moderate yields of the fused bicycles were obtained and reactions occurred with high regioselectivity and exo-diastereoselectivity.

The Bull group recently reported the synthesis of 2sulfonyl oxetanes, designed as desirable fragments for fragment-based drug discovery. ${ }^{18}$ Traditional cyclization approaches to synthesize these compounds were unsuitable due to the instability of the required intermediates. Therefore, a $\mathrm{C}-\mathrm{C}$ bond forming cyclization was developed, which had not been previously investigated for oxetane synthesis (Scheme 4a). An appropriate cyclization precursor was prepared in 3-steps from readily available chloromethyl aryl-sulfides. Deprotonation to generate the sulfone stabilized carbanion effected smooth cyclization. Excellent yields of the desired 2-sulfonyl oxetanes were obtained using LiHMDS (1.1 equiv) in $\mathrm{THF}$ at $0{ }^{\circ} \mathrm{C}$ on gram scales.

Further substituents were introduced on the 2-sulfonyl oxetanes through deprotonation and reaction with electrophiles (Scheme 4b). ${ }^{18,19}$ Two different sets of conditions were developed; LiHMDS or $n$-BuLi at low temperature depending on the compatibility with the electrophiles, providing 2,2-disubstituted oxetanes in excellent yields. Suzuki cross-coupling of the chlorophenyl containing oxetane (in Scheme 4) was also achieved to afford bi-aryl derivatives in good yields (not shown).

We proposed that this strategy may provide more facile access to more functionalized and highly substituted oxetane derivatives, and overcome some of the limitations of $\mathrm{C}-\mathrm{O}$ cyclization approaches. To enable this, we exploited an $\mathrm{O}-\mathrm{H}$ insertion to expedite the synthesis. ${ }^{20}$ Targeting 2,2-oxetane dicarboxylate, the cyclization precursor could be prepared in 1 step from diethyl diazomalonate and 2-bromoethanol using catalytic rhodium acetate dimer (Scheme 5). The $\mathrm{O}-\mathrm{H}$ insertion occurred selectively in high yield with no indication of competing epoxidation. Intramolecular cyclization with the malonate anion displacing the bromide was effective using $\mathrm{NaH}$ (1.2 equiv) in $\mathrm{DMF}$ at $0{ }^{\circ} \mathrm{C}$ in $1 \mathrm{~h}$, providing a rapid 2 -step route to 
oxetane derivatives. Bromides were shown to afford improved yields in the cyclization versus iodide and tosylate leaving groups.

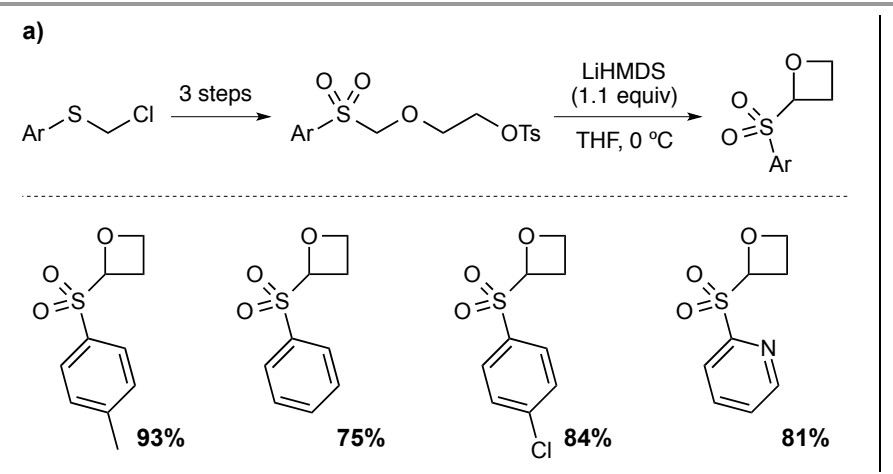

b)

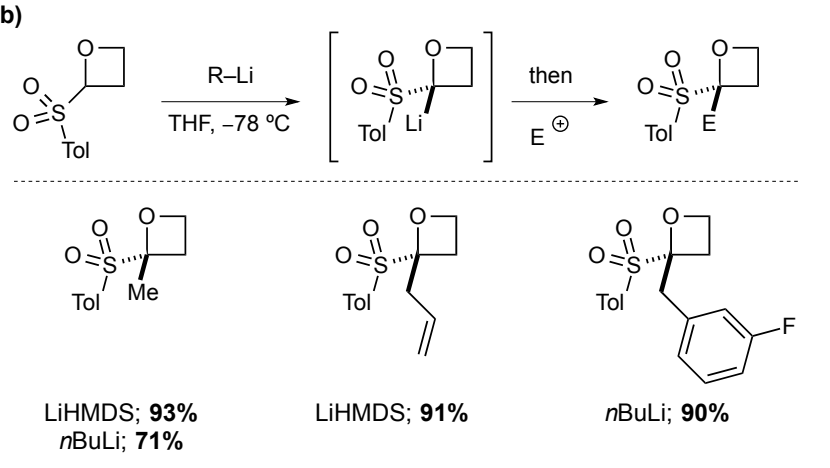

Scheme 4 Synthesis and functionalization of 2-sulfonyl oxetanes.

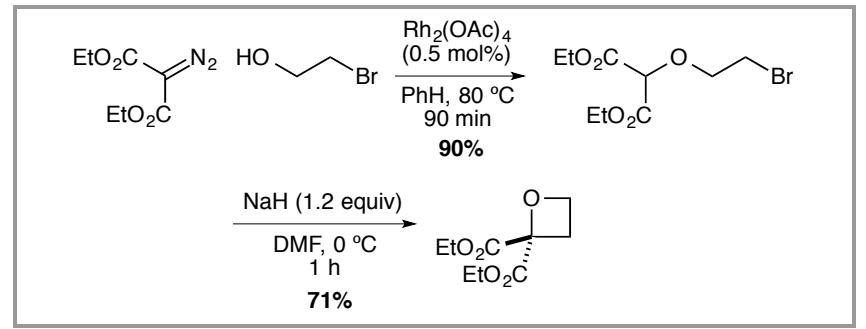

Scheme 5 Synthesis of 2,2-diethyl oxetane dicarboxylate by $\mathrm{O}-\mathrm{H}$ insertion/C-C bond forming cyclization.

The introduction of substituents onto 2-bromoethanol was then examined to form chiral oxetanes. Both aryl and alkyl substituted $\beta$-bromohydrins were readily prepared on route to 2,2,4-trisubsituted oxetanes (Scheme 6). The $\mathrm{O}-\mathrm{H}$ insertion was generally successful across the range of substrates, with the same conditions employed as for the unsubstituted example. The cyclization required a longer reaction time $(16 \mathrm{~h})$ and higher temperature $\left(25^{\circ} \mathrm{C}\right)$ to achieve complete conversion and excellent yields. A wide range of substituted aryl groups was well tolerated (Scheme 6a), including halogenated, electron-rich and electron-poor aromatic substituents in similarly high yields. The sequence was performed with the enantioenriched phenyl-substituted $\beta$-bromohydrin. As expected, the ee was perfectly retained through both the $\mathrm{O}-\mathrm{H}$ insertion and cyclization steps, accessing the enantioenriched oxetane. As such, enantioenriched oxetanes are readily available from enantioenriched $\beta$-bromohydrins. ${ }^{21}$ The synthetic sequence was also high yielding on a gram scale.

Alkyl substituents were well tolerated through the reaction sequence (Scheme $6 \mathrm{~b}$ ). Several functional groups were introduced at the 4-position of the oxetane, including ethers, a bromomethyl group, and a trifluoromethyl group. Chlorides were also viable leaving groups for oxetane synthesis (Scheme 6c). From the corresponding chlorohydrins, a chloromethyl group and also a silyl protected alcohol were introduced at the 4-position, with high yields over both steps.

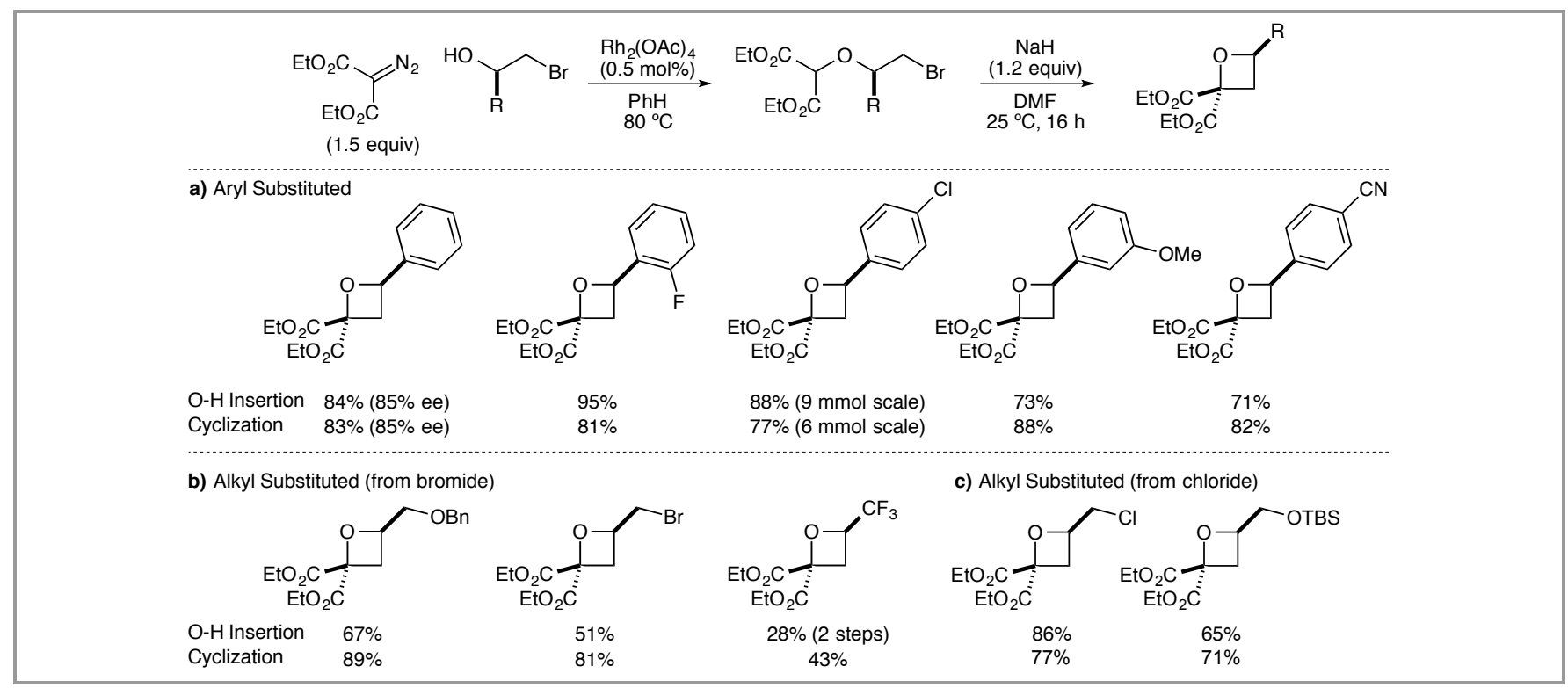

Scheme 6 Synthesis of 2,2,4-trisubstituted oxetane derivatives (selected examples). 


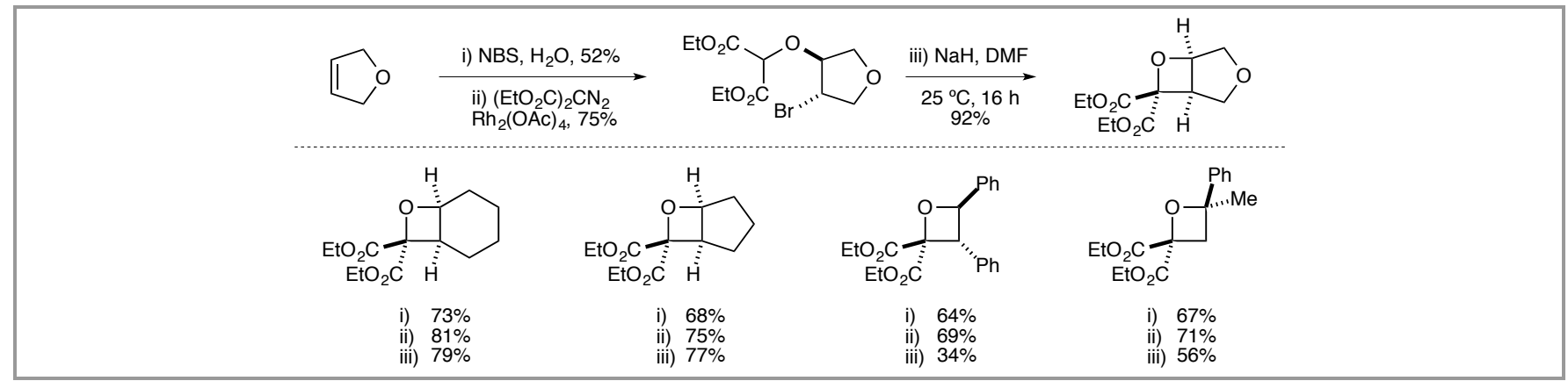

Scheme 7 Synthesis of tetrasubstituted oxetanes by $\mathrm{O}-\mathrm{H}$ insertion/C-C bond forming cyclization

This method was expanded further to the synthesis of sterically congested tetrasubstituted oxetane derivatives, demonstrating that the cyclization was not limited to primary halides. Using cyclic alkenes, to access fused oxetane derivatives, anti-substituted bromohydrins were generated on treatment with NBS/ $\mathrm{H}_{2} \mathrm{O}$ (Scheme 7). From 2,6-dihydrofuran, cyclohexene and cyclopentene the corresponding fused oxetanes were generated with high yields across each of the 3step sequences. From trans-stilbene, 2,2-diester-3,4diphenyl oxetane was prepared as a single antidiastereoisomer. Similarly, the corresponding 2,2,4,4substituted oxetane was prepared from $\alpha$ methylstyrene.

The diester products were further elaborated to generate oxetane containing fragments and building blocks of interest in drug discovery (Scheme 8). The diester functionality could be reduced to the diol using in situ generated $\mathrm{LiBH}_{4}$ (Scheme 8a). This was converted to the mono-tosylate and subsequent Williamson cyclization afforded an unusual angular bis-oxetane spirocycle. The diester successfully underwent Krapcho decarboxylation using $\mathrm{LiCl}$, affording the readily separable cis- and trans-2,4substituted oxetanes (Scheme 8b). Mono-hydrolysis of the diester moiety with $\mathrm{NaOH}$ afforded the monocarboxylate sodium salt which was directly coupled with morpholine using HATU (Scheme 8c). Finally, the bromomethyl oxetane was reacted with sodium azide to form the primary alkyl azide, which underwent a Huisgen azide cycloaddition with phenyl acetylene using copper sulfate (Scheme 8d).

In summary, several methods have been developed for the preparation of highly substituted oxetane derivatives. In addition to developments in more traditional $\mathrm{C}-\mathrm{O}$ bond forming strategies, $\mathrm{C}-\mathrm{C}$ bond forming cyclization has emerged as a powerful approach to oxetane synthesis. Highly substituted oxetanes containing suitable functionality for further derivatization, as well as enantioenriched examples, have been prepared by this approach. Given the interest in oxetane structures and properties, it is likely further methods will be developed for the efficient preparation of oxetanes. This will further enable the full study and exploitation of oxetanes as motifs for synthesis and medicinal chemistry.

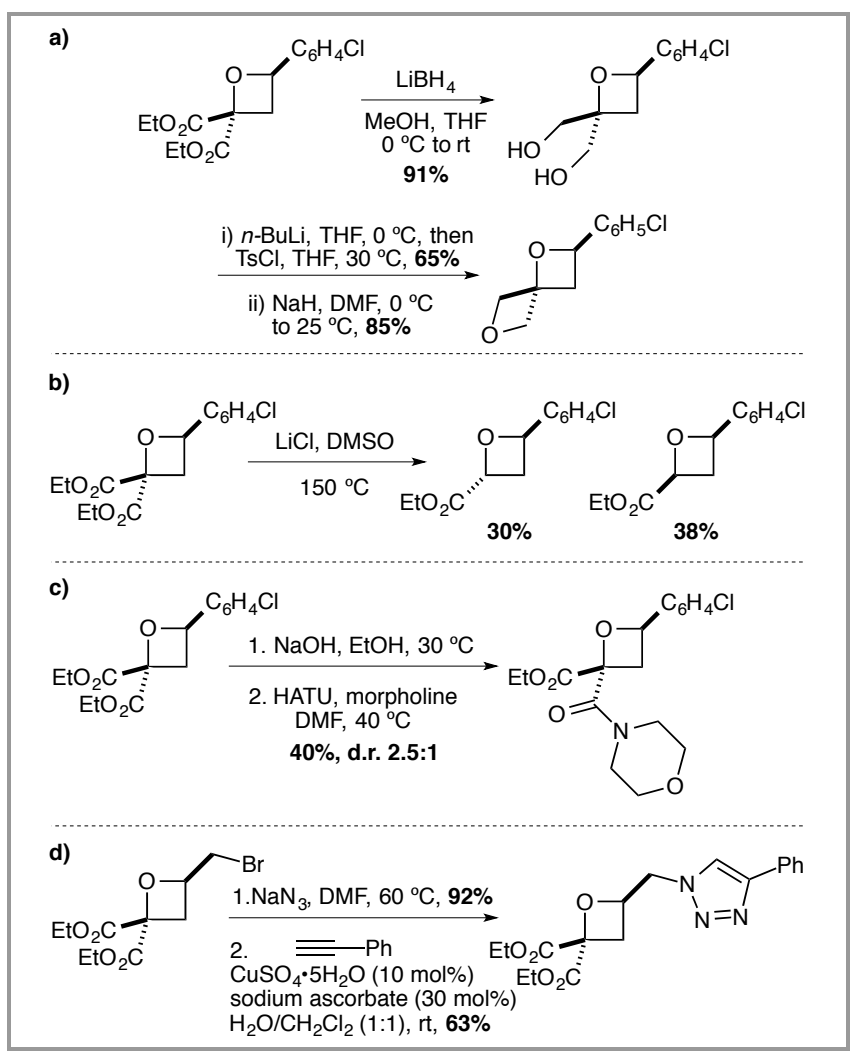

Scheme 8 Selected examples of derivatization of diester oxetanes.

\section{Acknowledgment}

We thank the EPSRC for a Career Acceleration Fellowship (EP/J001538/1; to JAB) and a DTA studentship (to OAD), and Imperial College London.

\section{References}

(1) a) Ghosh, B.; Urban, M. W. Science 2009, 323, 1458. b) Shibutani, R.; Tsutsumi, H. J. Power Sources 2012, 202, 369. c) Schulte, B.; Dannenberg, C. A.; Keul, H.; Möller, M. J. Poly. Sci., Part A: Polym. Chem. 2013, 51, 1243.

(2) For selected recent examples, see: a) Gronnier, C.; Kramer, S.; Odabachian, Y.; Gagosz, F. J. Am. Chem. 
Soc. 2012, 134, 828. b) Ruider, S. A.; Müller, S.; Carreira, E. M. Angew. Chem. Int. Ed. 2013, 52, 11908.

(3) Wang, Z.; Chen, Z.; Sun, J. Org. Biomol. Chem. 2014, 12,6028 .

(4) Burkhard, J. A.; Wuitschik, G.; Rogers-Evans, M.; Müller, K.; Carreira, E. M. Angew. Chem. Int. Ed. 2010, 49, 9052.

(5) a) Wuitschik, G.; Rogers-Evans, M.; Müller, K.; Fischer, H.; Wagner, B.; Schuler, F.; Polonchuk, L.; Carreira, E. M. Angew. Chem. Int. Ed. 2006, 45, 7736. b) Wuitschik, G.; Carreira, E. M.; Wagner, B.; Fischer, H.; Parrilla, I.; Schuler, F.; Rogers-Evans, M.; Müller, K. J. Med. Chem. 2010, 53, 3227.

(6) a) For Taxol see: Wani, M. C.; Taylor, H. L.; Wall, M. E. J. Am. Chem. Soc. 1971, 93, 2325. b) For Oxetin (glutamine antimetabolite) see: Ōmura, S.; Murata, M.; Imamura, N.; Iwai, Y.; Tanaka, H. J. Antibiot. 1984, 37, 1324.

(7) For a recent study on oxetane metabolic stability: Stepan, A. F.; Karki, K.; McDonald, W. S.; Dorff, P. H.; Dutra, J. K.; DiRico, K. J.; Won, A.; Subramanyam, C.; Efremov, I. V.; O’Donnell, C. J.; Nolan, C. E.; Becker, S. L.; Pustilnik, L. R.; Sneed, B.; Sun, H.; Lu, Y.; Robshaw, A. E.; Riddell, D.; O'Sullivan, T. J.; Sibley, E.; Capetta, S.; Atchison, K.; Hallgren, A. J.; Miller, E.; Wood, A.; Obach, R. S. J. Med. Chem. 2011, 54, 7772.

(8) a) Duncton, M. A. J.; Estiarte, M. A.; Johnson, R. J.; Cox, M.; O’Mahony, D. J. R.; Edwards, W. T.; Kelly, M. G. J. Org. Chem. 2009, 74, 6354. b) Duncton, M. A. J.; Estiarte, M. A.; Tan, D.; Kaub, C.; O’Mahony, D. J. R.; Johnson, R. J.; Cox, M.; Edwards, W. T.; Wan, M.; Kincaid, J.; Kelly, M. G. Org. Lett. 2008, 10, 3259.

(9) Carreira, E. M.; Fessard, T. C. Chem. Rev. 2014, 114, 8257.

(10) a) Du, J.; Chun, B.-K.; Mosley, R. T.; Bansal, S.; Bao, H.; Espiritu, C.; Lam, A. M.; Murakami, E.; Niu, C.; Micolochick Steuer, H. M.; Furman, P. A.; Sofia, M. J. J. Med. Chem. 2014, 57, 1826. b) Jonckers, T. H. M.; Vandyck, K.; Vandekerckhove, L.; Hu, L.; Tahri, A.; Van Hoof, S.; Lin, T.-I.; Vijgen, L.; Berke, J. M.; Lachau-Durand, S.; Stoops, B.; Leclercq, L.; Fanning,
G.; Samuelsson, B.; Nilsson, M.; Rosenquist, Å.; Simmen, K.; Raboisson, P. J. Med. Chem. 2014, 57, 1836.

(11) Wuitschik, G.; Rogers-Evans, M.; Buck1, A.; Bernasconi, M.; Märki, M.; Godel, T.; Fischer, H.; Wagner, B.; Parrilla, I.; Schuler, F.; Schneider, J.; Alker, A.; Schweizer, W. B.; Müller, K.; Carreira, E. M. Angew. Chem. Int. Ed. 2008, 47, 4512.

(12) Burkhard, J. A.; Guérot, C.; Knust, H.; Carreira, E. M. Org. Lett. 2012, 14, 66.

(13) a) Okuma, K.; Tanaka, Y.; Kaji, S.; Ohta, H. J. Org. Chem. 1983, 48, 5133. b) Butova, E. D.; Barabash, A. V.; Petrova, A. A.; Kleiner, C. M.; Schreiner, P. R.; Fokin, A. A. J. Org. Chem. 2010, 75, 6229.

(14) Sone, T.; Lu, G.; Matsunaga, S.; Shibasaki, M. Angew. Chem. Int. Ed. 2009, 48, 1677.

(15) a) Abe, M. J. Chin. Chem. Soc. 2008, 55, 479. b) D'Auria, M.; Racioppi, R. Molecules 2013, 18, 11384.

(16) a) Vogt, F.; Jödicke, K.; Schröder, J.; Bach, T. Synthesis 2009, 4268. b) Bach, T. Liebigs Ann./Recl. 1997, 1627. c) Bach, T. Synlett 2000, 1699.

(17) Griesbeck, A. G.; Franke, M.; Neudörfl, J.; Kotaka, H Beilstein J. Org. Chem. 2011, 7, 127.

(18) Morgan, K. F.; Hollingsworth, I. A.; Bull, J. A. Chem. Commun. 2014, 50, 5203.

(19) For other studies on deprotonation of oxetanes and trapping with electrophiles, see: a) Coppi, D. I.; Salomone, A.; Perna, F. M.; Capriati, V. Chem. Commun. 2011, 47, 9918. b) Geden, J. V; Beasley, B. O.; Clarkson, G. J.; Shipman, M. J. Org. Chem. 2013, $78,12243$.

(20) Davis, O. A.; Bull, J. A. Angew. Chem. Int. Ed. 2014, 53, 14230.

(21) For enantioenriched bromohydrins, see: a) Wei, S.; Messerer, R.; Tsogoeva, S. B. Chem. Eur. J. 2011, 17, 14380. b) Ren, J.; Dong, W.; Yu, B.; Wu, Q.; Zhu, D. Tetrahedron: Asymmetry 2012, 23, 497. c) Zhou, Y.; Gao, G.; Song, Y.; Qu, J. Synth. Commun. 2014, 44, 1515 . 
James A. Bull is a Research Fellow at Imperial College London. His research focuses on the development of strategies to access novel heterocycles of interest in drug discovery. He obtained his MSci degree from the University of Cambridge, then spent a year working at GlaxoSmithKline. He returned to University of Cambridge to obtain his $\mathrm{PhD}$ in organic chemistry under the supervision of Professor Steven V. Ley on the total synthesis of antifungal natural product bengazole A. In 2007 he joined the group of Professor André B. Charette as a Postdoctoral Fellow at Université de Montréal. He joined Imperial College London as a Ramsay Memorial Research Fellow in 2009, then in 2011 he was awarded an EPSRC Career Acceleration Fellowship.

Owen A. Davis studied Chemistry at Imperial College London and obtained a First Class MSci degree in 2012. He then continued with his PhD studies at Imperial College London with Dr James Bull. He is currently in his final year of his $\mathrm{PhD}$ studies on the synthesis and functionalization of small ring heterocycles.

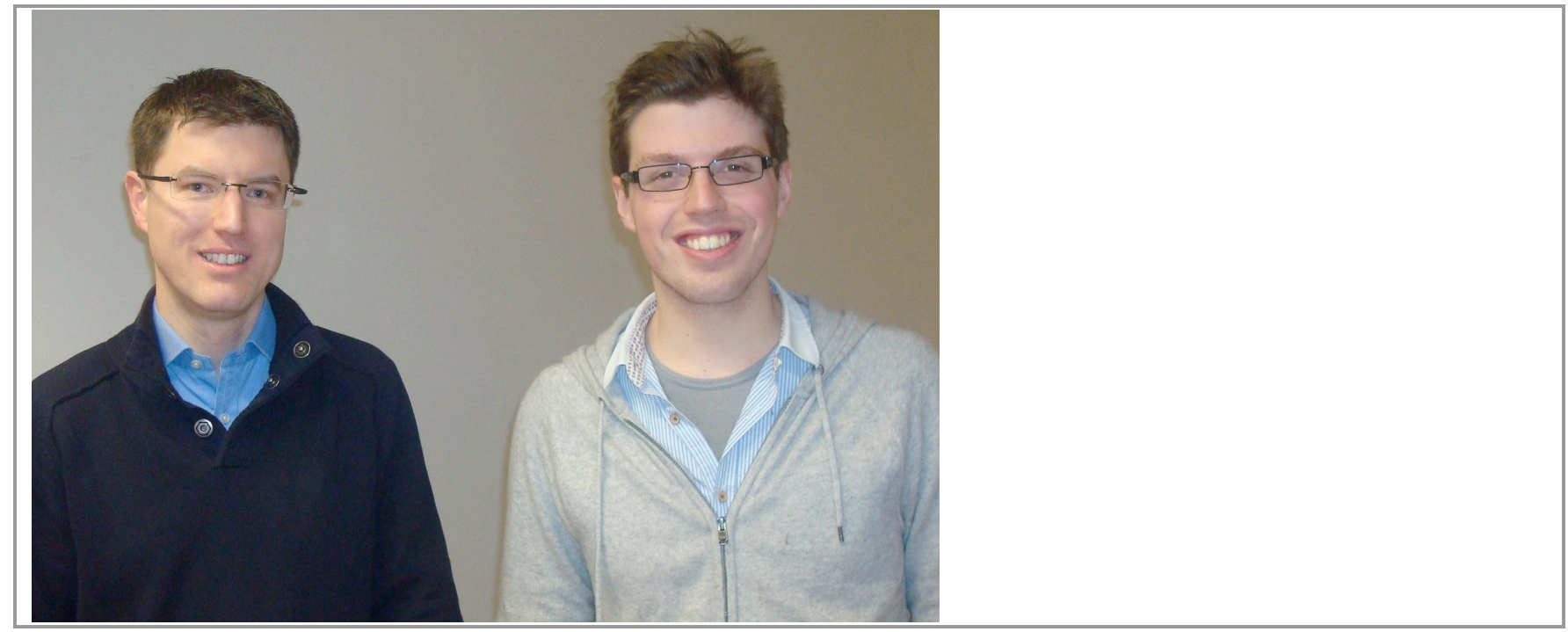

Synthesis of 2-substituted oxetanes

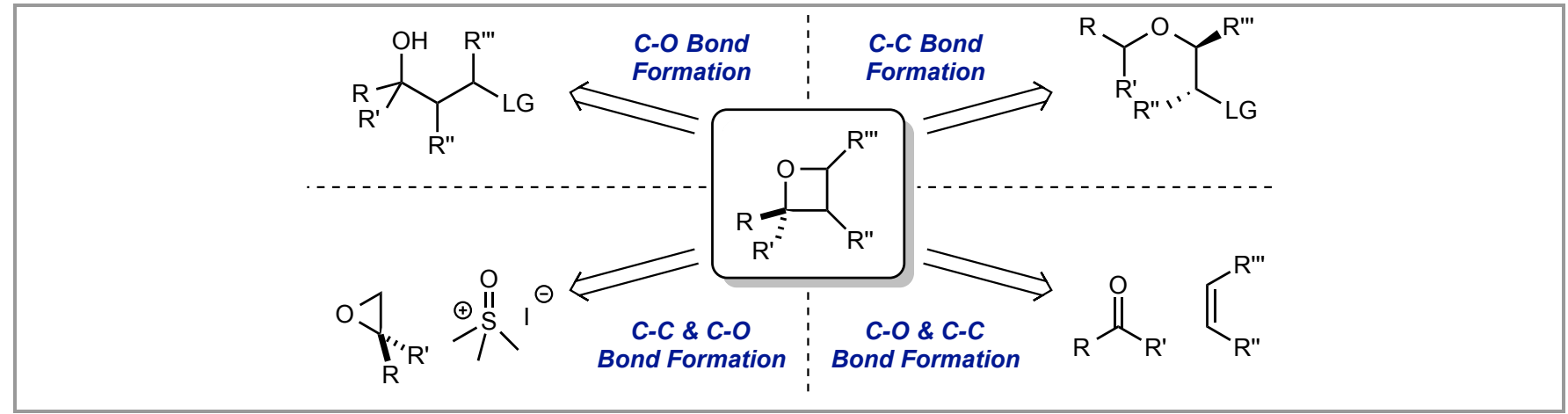

Graphical Abstract 